\title{
Postpartum Depression in Immigrant Hispanic Women: A Comparative Community Sample
}

\author{
Laura Mae Shellman \\ Brigham Young University - Provo
}

Follow this and additional works at: https://scholarsarchive.byu.edu/etd

Part of the Nursing Commons

\section{BYU ScholarsArchive Citation}

Shellman, Laura Mae, "Postpartum Depression in Immigrant Hispanic Women: A Comparative Community Sample" (2012). Theses and Dissertations. 3244.

https://scholarsarchive.byu.edu/etd/3244

This Thesis is brought to you for free and open access by BYU ScholarsArchive. It has been accepted for inclusion in Theses and Dissertations by an authorized administrator of BYU ScholarsArchive. For more information, please contact ellen_amatangelo@byu.edu. 
Postpartum Depression in Immigrant Hispanic Women:

A Comparative Community Sample

Laura M. Shellman

A thesis submitted to the faculty of

Brigham Young University

in partial fulfillment of the requirements for the degree of

Master of Science

Renea L. Beckstrand, Chair

Karlen E. Luthy

Donna S. Freeborn

College of Nursing

Brigham Young University

June 2012

Copyright () 2012 Laura M. Shellman

All Rights Reserved 


\title{
ABSTRACT \\ Postpartum Depression in Immigrant Hispanic Women: \\ A Comparative Community Sample
}

\author{
Laura M. Shellman \\ College of Nursing, BYU \\ Master of Science
}

Purpose: This study was initiated to verify whether a remarkably high rate of postpartum depression (PPD), previously found in immigrant Hispanic women receiving health care at a community clinic, would also be found in a community sample with a similar demographic.

Data Sources: Sixty immigrant Hispanic women who had recently given birth were recruited from local community settings. The Beck Postpartum Depression Screening ScaleSpanish version (PPDS-S) and the General Acculturation Index (GAI) were used to screen for PPD symptoms and to collect demographic data. These data were then compared with previously published data from the community clinic sample.

Conclusions: Sixty percent of the immigrant Hispanic women in our community sample showed significant PPD symptoms as scored on the Beck PPDS-S. There was no significant difference found in demographics or in types of PPD symptoms between the clinic sample and the community sample. Of all the demographic data, the only statistically significant positive predictive factor for increased PPD symptoms was having a previous history of depression. In addition, 54\% of the sample had an elevated symptom content profile score for suicidal thinking.

Implications for Practice: Health practitioners should be aware of a potentially high rate of PPD in this population, especially in light of previously studied increased rates of suicide attempts in Latinas. If a prior history of depression is predictive of PPD, it is possible that many of the mothers in our sample suffered from depression prior to the postpartum period, but were not appropriately diagnosed or treated. Recommendations for outreach and further research are discussed. In particular, further research regarding the prenatal prevalence of depression in immigrant Hispanic women is recommended in order to further understand the high incidence of PPD.

Keywords: postpartum depression, depression, mental health, Hispanic, Latina, suicide, prenatal, perinatal, screening, health intervention, social support, stigma, outreach, cultural competence 


\section{ACKNOWLEDGMENTS}

I would like to particularly thank the members of my thesis committee for guiding me and helping me to complete this process. My committee chair, Dr. Renea Beckstrand patiently gave me direction and help whenever I needed it. I also hold her to be primarily responsible for

my receiving a Graduate Research Fellowship because I would never have applied for the award if not for her encouragement. Many thanks go to BYU Graduate Studies for funding the fellowship. Finally, I want to thank and acknowledge my husband, Jacob Shellman, who was not only such a great help in the technical aspects of translating and so forth, but also such a great support in all that was needed at home so that I could complete this thesis and degree. Thank you. 


\section{TABLE OF CONTENTS}

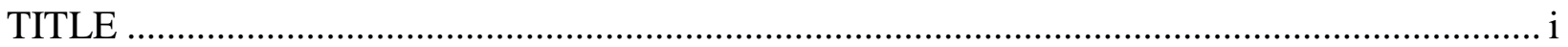

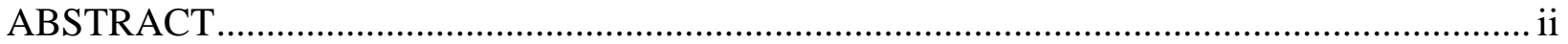

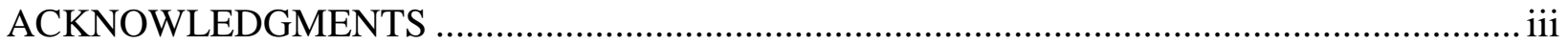

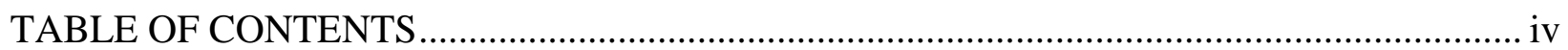

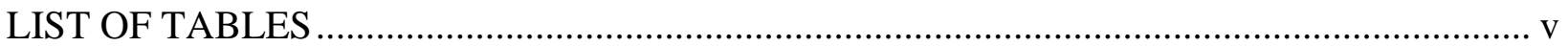

Postpartum Depression in Immigrant Hispanic Women: A Comparative Community Sample..... 1

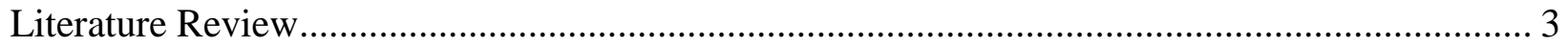

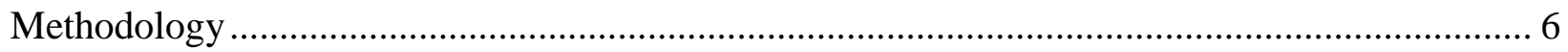

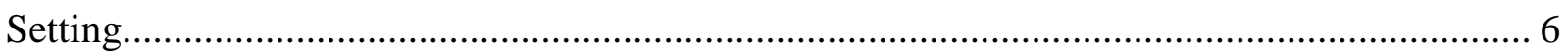

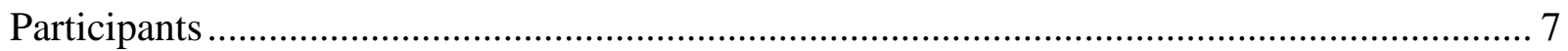

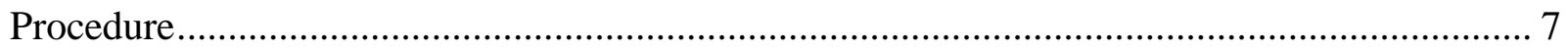

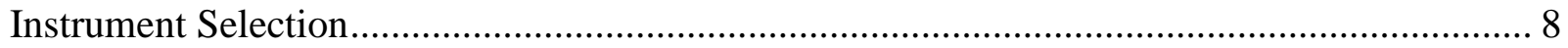

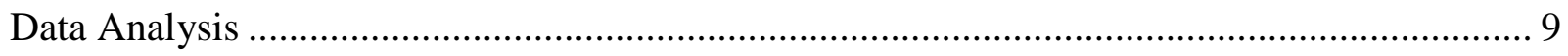

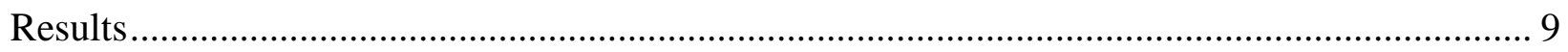

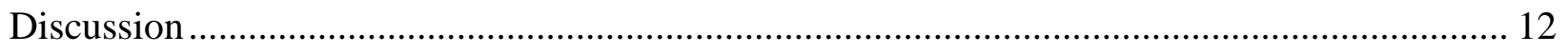

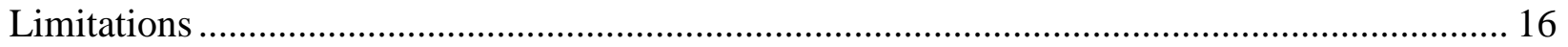

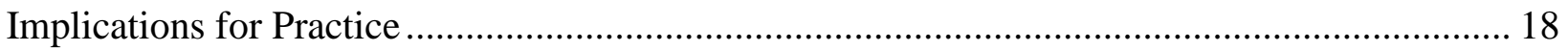

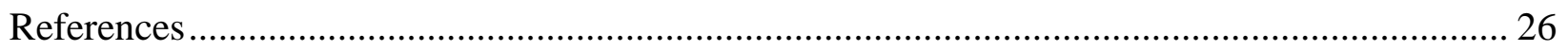




\section{LIST OF TABLES}

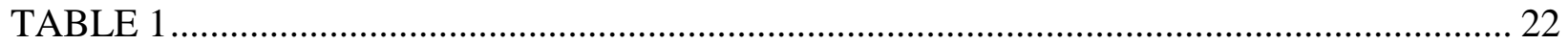

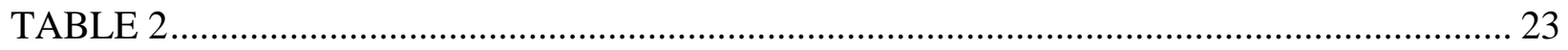

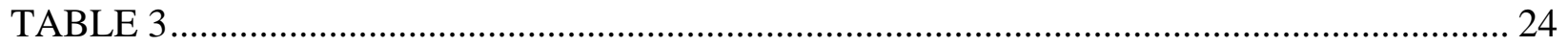

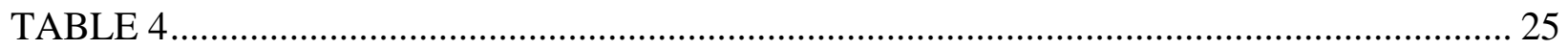




\section{Postpartum Depression in Immigrant Hispanic Women:}

\section{A Comparative Community Sample}

Researchers agree that postpartum depression (PPD) is the most common complication of childbirth, yet despite its far-reaching consequences it often goes unrecognized and untreated (Dennis \& Chung-Lee, 2006; O’Hara, 2009; Sit \& Wisner, 2009). The Centers for Disease Control and Prevention (CDC) Pregnancy Risk Assessment Monitoring System (PRAMS) reported the prevalence of significant PPD symptoms throughout the United States (U.S.). Using data gathered between 2004 and 2005 from a representative sample of the population in 17 states, self-reported PPD symptoms were present in 11.7-20.4\% of the sample (Centers for Disease Control [CDC], 2008). The PRAMS study also found that Hispanic women in Utah had higher rates of PPD symptoms (16.7\%) when compared with non-Hispanic white women (12.8\%), a finding consistent with the other states surveyed. No differentiation, however, was made between foreign born or U.S. born Hispanics in the study. Characteristics found to be associated with PPD symptoms in all races included young maternal age, being unmarried, having a lower level of education, Medicaid coverage for delivery, previous physical abuse, or traumatic, emotional and/or financial stress during pregnancy (CDC, 2008). These characteristics have also been identified within immigrant Hispanic populations (Fung \& Dennis, 2010; Heilemann, Frutos, Lee, \& Kury, 2004; Howell, Mora, Horowitz, \& Leventhal, 2005).

The rising Utah Hispanic population demonstrates the need to address their unique prenatal needs. In fact, during the 2010 census 13\% of Utah’s population identified themselves as Hispanic, an increase of 68.7\% over the previous 10 years (Motel, 2012). Korinek and Smith (2011) found that all groups of Utah Hispanic women (undocumented immigrants, documented immigrants, and American-born) obtained prenatal care at lower levels than non-Hispanic white 
women. This underscores that the immigrant Hispanic community in Utah is a vulnerable population.

A recent study using the Spanish Version of the Beck Postpartum Depression Screening Scale (PDSS-S) conducted at a community health center in a central Utah county found a startlingly high prevalence of significant PPD symptoms. Of the 96 immigrant Hispanic women in the convenience sample, 54\% were found to have significant symptoms of PPD (Lucero, Beckstrand, Callister, \& Birkhead, 2012). The percentage of subjects with high scores on the Beck PPDS-S was considerably greater than the $16.7 \%$ of Utah Hispanic women who selfreported PPD symptoms in the PRAMS study (CDC, 2008).

Lucero and colleagues (2012) postulated that the high prevalence of PPD symptoms might be attributable to the convenience sample: women actively seeking health care in a clinic setting. To test this hypothesis we proposed conducting a similar study recruiting strictly from a community setting. The purpose of this study, therefore, was to (1) determine the prevalence of significant PPD symptoms in a community sample of Hispanic women and (2) to compare those findings with the previously gathered data from the clinic sample. We hypothesized that the community sample would show a significantly lower prevalence of PPD symptoms than had been found in the clinic sample.

In addition, Lucero et al. (2012) recommended that additional demographics be studied to determine whether or not commonalities existed that might indicate risk factors for PPD. The identification of such risk factors could then be used for identifying and appropriately treating Hispanic women with the potential for PPD. Therefore, it was hoped that the data of the clinic and community samples could be combined and analyzed to determine whether there were any 
statistically significant demographic features that could be associated with the presence of significant PPD symptoms.

Verifying that a high prevalence of PPD exists within the local immigrant Hispanic community, or determining if any demographic predictor of PPD symptoms could be found might be of benefit to practitioners in deciding how to most effectively screen their increasing numbers of immigrant Hispanic patients and direct the disbursement of limited perinatal support resources.

\section{Literature Review}

The consequences of unrecognized, untreated PPD to individuals, families, and communities are significant. Left untreated, PPD symptoms can hinder the relationship between mother and child, lead to increased maternal substance abuse, and decrease overall familial satisfaction and parental confidence. Furthermore, PPD places infants at higher risk for maternalinfant attachment issues and can adversely affect outcomes in social, behavioral, cognitive, and other aspects of childhood development (Boyd, Zayas, \& McKee, 2006; O’Hara, 2009; Sit \& Wisner, 2009).

Hispanic women living in the U.S. have come to the attention of PPD researchers as the U.S. Hispanic population has increased so rapidly through both immigration and a high birth rate. Using data from the 2010 census, the Pew Hispanic Center found that between 2000 and 2010, the number of foreign born Hispanics in the U.S. increased by $33.2 \%$ and the number of native born Hispanics increased by 51\%. To further illustrate the high birth rate in the Hispanic population, 23\% of U.S. births in 2010 were attributed to Hispanic women, while only $16.4 \%$ of the total U.S. population was Hispanic (Motel, 2012). 
Researchers also report numerous risk factors for PPD prevalent within the Hispanic population. Several stressors commonly found in the daily life of many immigrant Hispanic mothers increase a woman's risk of PPD: financial hardship, unemployment, stressful life events including emotional or physical trauma prior to or during immigration, poor housing, lack of higher education, young maternal age, and single status. Other stressors include difficulties related to the acculturation process such as perceived cultural discrimination, lack of social support and networks, and language barriers (Davila, McFall, \& Cheng, 2009; Fung and Dennis, 2010; Rich-Edwards et al., 2006; Surkan, Peterson, Hughes, \& Gottlieb, 2006). Recent immigrants may be particularly at risk because the social supports and networks utilized in their culture of origin are no longer present (Heilemann et al., 2004; Martinez-Schallmoser, Telleen, \& MacMullen, 2003). Some immigrant women leave children in their native countries which has been found to lead to increased risk for depression (Miranda, Siddique, Der-Martirosian, \& Belin, 2005).

Interestingly, studies have found that while Hispanic women may be at increased risk for PPD, they are also less likely to recognize or acknowledge their own symptoms. In addition, health care providers are less likely to identify PPD symptoms in Hispanic women (Chaudron, Kitzman, Peifer, Morrow, Perez, \& Newman, 2005; Howell et al., 2005). If health care providers do not routinely screen for PPD, Hispanic American women are not likely to reveal their PPD symptoms (Chaudron et al., 2005). Even when PPD screening occurs, less acculturated Hispanic patients may not understand the questions which could lead to misdiagnosis. In addition, practitioners may not identify PPD symptoms due to language misunderstandings or the patient's hesitance to acknowledge her symptoms (Chaudron et al., 2010). 
Immigrant women can view their PPD symptoms through varied cultural lenses and may perceive those symptoms as a threat to their idea of the ideal mother (Abrams \& Curran, 2011). As a result, the stigma commonly associated with a mental illness, such as depression, may prevent immigrant Hispanic women from acknowledging their illness or from seeking care for it. Even if stigma is not a barrier, many other barriers exist that may prevent adequate treatment for PPD. Some barriers to health care common to the immigrant Hispanic population include: lack of insurance coverage, inadequate transportation and childcare, improper legal documentation, and limited knowledge regarding the U.S. health care system or where affordable care can be accessed (Cabassa \& Zayas, 2007; Callister, Beckstrand, \& Corbett, 2011; Fung and Dennis, 2010; Wallace, Pomery, Latimer, Martinez, \& Salovey, 2010). Even when Hispanic women receive care for PPD, they are less likely to receive follow-up treatment or to refill a prescription for PPD than white, non-Hispanic women (Kozhimannil, Trinacty, Busch, Huskamp, \& Adams, 2011). Furthermore, Hispanic women often delay health care in general because they first solicit advice from their family and friends and may use these traditional, informal sources for help before seeking medical care from the health system at large (Cabassa \& Zayas, 2007; Callister et al., 2011; Garcés, Scarinci, \& Harrison, 2006).

With so many difficulties preventing Hispanic women from seeking treatment for their depression, it is especially important for health care providers to demonstrate cultural sensitivity and cultural competence. Sanchez-Birkhead, Kennedy, Callister, and Miyamoto (2011) interviewed immigrant Hispanic women regarding perceived discrimination from health care providers who were unfamiliar with Hispanic culture. The women stated that perceived discrimination led to stressful and sometimes long-lasting emotional barriers to seeking health care, and influenced where they chose to seek future care. Such negative experiences may further 
contribute to a decreased use of mental health services by Hispanic women thereby increasing their overall vulnerability as a population (Huang, Appel, \& Ai, 2011).

It has been proposed that increased acculturation in Hispanic women may play a role in increased self-recognition of PPD symptoms, thus increasing the likelihood that acculturated women will seek medical care for their PPD symptoms. For example, Heilemann et al. (2004) found that Hispanic women who had lived in the U.S. since childhood reported significantly more depressive symptoms than women who had spent their childhood in Mexico. However, it is difficult to determine whether these women actually experienced more overt symptoms of depression, or if they were simply more likely to recognize and report their symptoms. Davila, McFall and Cheng (2009) also found that higher levels of acculturation were associated with higher levels of reported symptoms of depression among Latinas; however, they also reported that research findings on the relationship between acculturation and PPD symptoms has been inconsistent. Additionally, many different definitions of acculturation exist, which may further contribute to the difficulty found in coming to a consensus on how such a complex and multifaceted concept relates to PPD (Beck, 2006; Thomson \& Hoffman-Goetz, 2009).

\section{Methodology}

\section{Setting}

Following institutional review board approval, a community convenience sample was recruited by inviting immigrant Hispanic women to participate in a survey as they arrived to shop at a community market in Utah. Participants were also recruited as they participated in Hispanic community fairs in the area. All data were collected between May of 2010 and November of 2011. 


\section{Participants}

The PDSS-S questionnaire requires that postpartum women choose responses based on how they have felt in the past 2 weeks (Beck \& Gable, 2003), so immigrant Hispanic women who were between 2 weeks and 1 year postpartum were invited to participate. To be eligible for participation, the women were required to identify themselves as Hispanic and be able to read Spanish. Exclusion criteria included those who had given birth within 2 weeks of the survey date or longer than 12 months of the survey date. No inquiry was made regarding immigration status.

\section{Procedure}

Recruitment and survey administration was performed by fluent Spanish-speaking investigators. An expert trained in the administration and scoring of the PDSS was present during survey administration. Eligible subjects were identified and then introduced to the study. Those who agreed to participate were provided with a consent form written in Spanish. Eligible participants who agreed to participate and signed the consent form were asked to complete questionnaires regarding postpartum depression symptoms, acculturation, and demographic information. Total time to complete all parts of the study was approximately 20 minutes. Participants were assured that the information they shared during the survey would be kept confidential.

Subjects were asked to first complete the PDSS-S which was scored on-site. If a participant's score was found to be significant for PPD symptoms, she was made aware of her score and was then referred to a community health center for free follow-up and treatment, if desired. While the PDSS-S was being scored, the women completed the General Acculturation Index (GAI) instrument. Data collection continued until 60 eligible study participants completed the study. Each participant was given a \$20 Visa gift card as compensation for their time. 


\section{Instrument Selection}

The PDSS-S is a well-known, frequently used tool for finding the prevalence of PPD in Hispanic women with well-established diagnostic accuracy (Reuland, Cherrington, Watkins, Bradford, Blanco, \& Gaynes, 2009). It is constructed using 35 Likert-style questions on a scale from strongly disagree (1), to strongly agree (5). The PDSS total score has a possible range from a minimum of 35 points to a maximum of 175 points. In the Spanish version of the PDSS (PDSS-S), women scoring between 35 and 59 points are considered to be within the normal limits of postpartum adjustment, however those scoring between 60 and 175 points are considered to have significant symptoms of postpartum depression (Beck \& Gable, 2005a).

Beck and Gable (2005b) found the 35-item scale to have a sensitivity of $84 \%$ and a specificity of $84 \%$ when a cut-off score of 60 was used to divide those who had a total PDSS score that was significant for either minor or major PPD symptoms from those who did not. Special care was taken during development of the PDSS-S to ensure adequate equivalence between the Spanish version and the original English version. The reliability and validity psychometrics in the Spanish version were found to be acceptable, albeit slightly lower than those found in the English version (Beck et al., 2003). Additionally, the PDSS-S was unable to establish a second cut-off point to differentiate between minor and major PPD symptoms as had been possible in the English version. In the English version, a score between 60 and 79 indicates that the patient has significant symptoms of PPD, while a score of 80 or higher strongly suggests the patient has major PPD (Beck et al., 2003).

Seven specific content dimension sub-scores can be derived from the total PDSS score. These include sleeping/eating disturbances, anxiety/insecurity, emotional lability, mental confusion, loss of self, guilt/shame, and suicidal thoughts (Beck \& Gable, 2005a). Le, Perry, and 
Ortiz (2010) found that the alpha reliabilities of the sub-scores ranged from 0.72 to 0.97 . It was determined that the 35 question PDSS-S had an overall internal consistency of 0.97 (Le, Perry, \& Ortiz, 2010).

The second instrument used by our study to collect demographic information was the GAI published by Balcazar, Castro, \& Krull, (1995). The GAI was specifically developed to be administered to Mexicans and Central Americans. The five-item instrument is easy to administer and quickly scored, has a Cronbach’s alpha of 0.82, and assesses measures of Spanish language use, ethnic composition of social circles, and pride in and exposure to the Hispanic culture (Thomson \& Hoffman-Goetz, 2009).

\section{Data Analysis}

SPSS version 19.0, 2010, for Microsoft Windows was used to analyze the data using descriptive and parametric statistics including frequencies, t-tests, crosstabs, and correlations.

\section{Results}

The demographics of our community sample are summarized in Table 1. Of the 59 subjects reporting age, the mean age was found to be 28.9 years ( $\mathrm{SD}=5.8$ years). Ages ranged from 17 to 39 years. The majority of the sample were of Mexican descent (78.3\%) and married (80\%). Most (84.7\%) had at least completed high school including 11 (18.6\%) who had completed a college degree.

Data taken from the GAI illustrated the immigrant nature of our population, with $60 \%$ of participants reporting having lived only in Latin America or mostly in Latin America during the first 21 years of life. Only three people in the sample (5\%) had lived exclusively in the U.S. for the first 21 years of life. Every subject in our sample reported that they had pride in their 
Hispanic heritage, with the vast majority (96.7\%) reporting being either proud or very proud of their heritage. The number of participants who spoke only Spanish, or Spanish-better-thanEnglish was $39(65 \%)$ and only 6.7\% $(n=4)$ of participants reported that their ability to speak English was better than their ability to speak Spanish.

Our data also illustrated a close-knit Hispanic community. The vast majority (96.7\%) of the sample reported that at least half or more of their circle of friends were Hispanic, while a majority of the sample (61.7\%) reported having a circle of friends that was mostly or almost totally Hispanic. Only 2 participants (3.3\%) reported having a mostly non-Hispanic circle of friends.

Upon scoring the PDSS-S, our community sample was found to have a mean total PDSS score of 75.77, well above the cut-off score of 60 established and supported by the PDSS-S for those who have significant depressive symptoms. Total PDSS scores in the sample ranged from 35 to 166 . Only $40 \%(n=24)$ of the sample had scores consistent with normal postpartum adjustment (scores between 35 and 59) and 60\% $(n=36)$ had scores that showed significant PPD symptoms (scores of 60 or higher). Additionally, of seven different symptom content profiles within the PDSS, suicidal thinking had the highest number of women ( $n=29$, or $48.3 \%$ ) responding above the established cut-off level, with a score high enough to warrant further evaluation.

Due to the alarmingly high number of elevated PDSS total scores, we opted to compare the PDSS scores between the community and the clinic samples using two strategies. First, we compared the total PDSS scores between the community and clinic sample after dividing them into the two groups supported by the PDSS-S. Second, in order to further distinguish the large 
and undifferentiated significant symptom group into more precise subcategories, we analyzed the PDSS total scores after dividing them into the three groups that would have been supported had these women taken the English version of the PDSS (normal adjustment = scores between 35 and 59, significant symptoms of PPD = scores between 60 and 79, and positive screening for major PPD = scores of 80 or greater). We felt that making this differentiation might give us more insight into the data than would be possible from the division of the sample into only two groups.

Using a t-test for independent samples, we compared the total PDSS scores of our community sample against the previously published data collected at a community health center (Lucero et al., 2012). No statistically significant difference was found between the mean PDSS scores of the community sample and the clinic sample (community mean score $=75.8$, clinic mean score $=68.6 ; \mathrm{t}-1.328(154)=1.33, p=.177, \alpha=.05)$ (see Table 2 ).

After dividing the community and clinic samples into the two groups supported by the PDSS-S (normal adjustment v. significant PPD symptoms), we performed a crosstabs and chisquare analysis and found no significant difference $\left(\chi^{2}(1)=.400, p<.05\right)$ between the two groups (see Table 3). A Phi was also calculated to look at effect size, and location (community v. clinic) was found to have a very small effect (.07) on the chance of having a high total PDSS score.

After dividing our community and clinic samples into the three groups supported only by the English version of the PDSS, a crosstabs and chi-square analysis were again completed. Again, there was no significant difference found between the three levels of PDSS scores by location $\left(\chi^{2}(2)=.448, p<.05\right)$ (see Table 4$)$. When the Phi was calculated for this second analysis, location of sample was found to have a small effect (.10) on the chance of having a high total PDSS score. 
Having established that there was no significant difference between the total PDSS scores of the community and clinic samples, we attempted to identify any demographic features found within the two groups that, when looked at as a whole, would be associated with having a high total PDSS score. In order to determine this association, the community and clinic data were combined to run correlations between all demographic variables and total PDSS scores to see if there were any demographic variables that might be associated with a high total PDSS score.

A t-test of the combined data showed a significant relationship $(p=.001)$ between total PDSS score and those subjects claiming a history of depression $(n=28)$. The mean total PDSS score of those with a history of depression was $103.0(\mathrm{SD}=41)$, and the mean total PDSS score of those without a history of depression $(\mathrm{n}=125)$ was $64.4(\mathrm{SD}=26.7)(\mathrm{t} 6.226(151), p=.001, \alpha$ $=.05$ ). This was the only demographic variable found to be a statistically significant predictor of having a high PDSS total score. No other t-test on any other demographic variable was found to be significant.

\section{Discussion}

Lucero et al. (2012) found a significant PPD symptom prevalence in 54\% of their clinic sample of immigrant Hispanic women. Our community sample, obtained within the same county with women of a similar demographic, confirmed these findings. With $60 \%$ of our sample showing significant symptoms of PPD, there was no significant difference between the total PDSS scores of the two samples. This lack of significant difference, regardless of whether the scores were divided into two sub-categories or three, effectively disproved our hypothesis that there would be a significant difference in mean total score between the two groups. 
Our findings are consistent with other studies that have found similarly high percentages of significant PPD symptoms when using the Beck PDSS-S as a screening tool. For example, Le et al. (2010) used the PDSS-S to screen 155 immigrant Hispanic women, primarily from El Salvador and other Central American countries. Using the same clinical cut-off score of 60, they found that $63.9 \%$ of their sample had significant symptoms of PPD. Beck \& Gable (2005b) found PDSS-S total score alpha reliabilities for Puerto Rican/Caribbean, Mexican, and Central/South American subgroups to be, respectively, .96, .95, and .95, so we may be assured that the results of our sample of women primarily of Mexican descent are reliable.

A recent study performed as part of a national survey also found significant PPD symptoms in $63 \%$ of the sample when using the PDSS-short form as a screening tool. The PDSS-short form has been found to have a strong correlation with the original 35-item PDSS ( $\mathrm{r}$ $=0.94)$ (Beck, Gable, Sakala \& Declercq, 2011). Interestingly, the large sample $(n=1,573)$ of this national survey was specifically selected to be ethnically representative of the child-bearing population of the U.S. and yet it found a very similar prevalence of elevated PPD symptoms (63\%) as was found in our sample limited to immigrant Hispanic women (60\%).

We focused our research on what we believed to be the most vulnerable population in our community: immigrant Hispanic women. Because of their multiple risk factors, we felt that immigrant Hispanic women in our community would have higher levels of PPD than their U.S.born counterparts. However, a well-documented phenomenon described as the "immigrant paradox” (Alegría et al., 2008, p. 359) maintains that immigrant Hispanic men and women, despite their poverty and difficult life experiences, are found to have lower levels of most psychiatric illnesses than do U.S.-born Hispanic or non-Hispanic white individuals in the U.S. (Alegría et al., 2008). The reason behind this paradox is not well understood. Our sample, made 
almost entirely of immigrant Hispanic women, had a very high prevalence of significant PPD symptoms. If the immigrant paradox holds true for PPD, we would expect to find even higher levels of PPD symptoms in the U.S. born Hispanic population of our community. Alegría, et al. (2008) does caution, however, against assuming that the immigrant paradox is applicable to all Hispanic populations.

Of particular concern was the high percentage (54\%) of women in our sample who had a symptom content profile score for suicidal thinking elevated enough to warrant further investigation. Lucero et al. (2012) found the same in 56.7\% of their sample. Le et al. (2010) found a similarly high percentage (58.7\%) which they attributed to high numbers of recent immigrants from El Salvador, a country with a history of war and unrest. However, our sample primarily from Mexico showed a similarly high percentage. This raises concern that increased risk for suicidal thinking may be widespread among different immigrant Hispanic groups. Even more concern is raised when these findings are seen in the context of other studies which have found increased rates of suicide among young Hispanic teens when compared with their nonHispanic peers (Zayas, Lester, Cabassa \& Fortuna, 2005), as well as high levels of suicidal thinking and behavior in Hispanic adult women (Chang, Sanna, Hirsch, \& Jeglic, 2010).

Researchers have discussed this high rate of suicidal behavior and are attempting to understand the reasons behind it (Chang, Sanna, Hirsch, \& Jeglic, 2010; Zayas \& Pilat, 2008). Chang et al. (2010) found that loneliness and difficult life events can lead to increased risk of suicidal behavior in Hispanic women. While health practitioners may not be able to eliminate difficult events from the lives of their Hispanic patients, social support programs may be developed to improve the connectedness of these women, thereby decreasing their feelings of loneliness and isolation that are an inherent part of the recent immigrant experience (Chang et 
al., 2010). In order to decrease the prevalence of suicidal thinking during the postpartum period, perhaps providers can inform women of local support groups during their prenatal visits and facilitate attendance at such meetings during the pregnancy and postpartum period. We recommend that communities encourage the formation of such support groups if none are currently available.

Many studies have found that a past history of depression is associated with increased risk of having PPD (Lara, Le, Letechipia, \& Hochhausen, 2009). We likewise found a significant relationship ( $p=.001$ ) between a past history of depression and the presence of significant PPD symptoms. Many of the risk factors that lead to PPD such as single status, low income, decreased access to care, and exposure to violence, may also increase risk of depression prenatally (Fortner, Pekow, Dole, Markenson, \& Chanson-Taber, 2011; Heilemann et al., 2004). If there is, in fact, such a high prevalence of PPD in our immigrant Hispanic population, it is likely that more of our sample may have been depressed prenatally than was reported.

Because of the high levels of PPD symptoms in our sample and the significant relationship between PPD symptoms and a history of depression, we recommend that screening for depression in immigrant Hispanic women begin prior to pregnancy, or at least during pregnancy, so that interventions and treatments may be in place prior to the postpartum period. Research to find the prevalence of prenatal depression in Hispanic women should be a priority. Of particular service to the immigrant Hispanic community would be research that can shed light on which perinatal interventions are found to be most successful in decreasing the risk for PPD symptoms. 
Knowing that depression during pregnancy reliably predicts depression in the postpartum period, and that pregnant women have frequent contact with health care providers through prenatal visits, Lara et al. (2009) recommend that pregnancy is an excellent time to intervene with depression screening and support. They further recommend that specific questions should be asked during the first prenatal visits regarding depression and suicidality so that appropriate interventions may supplement the standard of care in these primary care and obstetrical settings (Lara et al., 2009). We propose that depression screenings need not be limited to prenatal visits, but that visits for gynecological screenings or family planning are also appropriate venues for screening and discussing the presence of depressive symptoms.

\section{Limitations}

There are limitations within our study that deserve note. First, we gathered a small convenience sample in a community with little variation in demographics. The homogeneity of the sample, therefore, may make our data less generalizable to other immigrant minority groups. Second, even though great care was taken to select tools that would yield accurate and useable data, the value and usefulness of the tools must be carefully considered. Some of the limitations inherent in using the PDSS-S are discussed below.

Reuland et al. (2009) were concerned that the lengthy nature of the 35-item written English version of PDSS makes it difficult for subjects with low literacy to accurately participate. Logsdon and Hutti (2006) used Fry’s Readability Graph (Fry, 1968) to determine that the original English PDSS was written at a fourth grade level. No data for the Spanish version were found. We did not find literacy to be a problem, however, as our sample subjects had a generally high education level and fluent Spanish speakers were available to answer the few questions that were asked. 
Chaudron et al. (2010) expressed concern that the PDSS may be less useful in a clinic setting than it is for research. The PDSS form is lengthy and must be purchased, therefore clinics may be reluctant to use it as a screening tool when another that is shorter and free to providers, such as the Edinburgh Postnatal Depression Scale (EPDS), is available. In order to achieve greater consistency between research and clinical practice, it may be beneficial to research PPD using tools that are more likely to be used in the clinic setting.

Another weakness of using the PDSS-S is that, unlike the original English version of the PDSS which supports a second cut-off score of 80 allowing for the identification of major PPD with 94\% sensitivity and 98\% specificity (Beck \& Gable, 2001), the Spanish version has not been able to establish a similar cut-off score (Beck \& Gable, 2005b). We felt that using the PDSS-S cut-off score of 60 to split our sample into only two categories placed those who scored positively for PPD symptoms into such a large, undifferentiated group, that it limited the usefulness of our data and might lead to confusion regarding the true prevalence of major PPD in our community.

Similar questions about the usefulness and accuracy of the established cut-off score of the PDSS-S exist. Le et al. (2010) spoke of the "need to validate the use of the cut-off score of 60 for Spanish-speaking populations” (p. 256), and stated that "additional research is needed to further validate the PDSS-Spanish version in clinical research and community settings” (p. 249). A study of PPD symptoms in urban black women found that while the PDSS is very accurate in identifying major PPD (scores of 80 or above), their findings supported a cut-off score for minor depression to be 17 points higher than was recommended by the tool. They expressed concern that cut-off scores may need to be altered to more accurately reflect symptom significance among different cultural groups, and that having such a low number as a cut-off score might lead 
to unnecessary referrals in their population. They further recommended that the screening tool be used in conjunction with clinical evaluation to ensure accuracy (Chaudron et al., 2010).

Upon describing the results of developing and testing the PDSS-Spanish version, Beck and Gable (2005b) likewise mentioned the limitations that the lack of a second cut-off score would place on the ability to distinguish between milder forms of PPD and more severe, major PPD. They did feel, however, that the single cut-off score was still useful for research because even mothers with symptoms of PPD who may not meet criteria for major PPD may still suffer substantial psychosocial problems due to their symptoms (Beck \& Gable, 2005b).

We acknowledge the weaknesses of the instrument, however we believe that the high prevalence of significant PPD symptoms found in our subjects remains a cause for concern. For example, 36.7\% ( $\mathrm{n}=22$ ) of our sample had total PDSS scores greater than 80 which is the cut-off score used in the English version of the PDSS to indicate a likelihood of having major PPD. We propose that communities around the U.S. should not take these findings lightly.

\section{Implications for Practice}

We recommend that communities and health practitioners everywhere take note of evidence-based research regarding what interventions have been successful in reducing PPD symptoms in Hispanic women and strive to achieve similar positive outcomes within their own areas of influence. Interventions can take many forms and may include reducing or eliminating barriers to treatment, reducing stigma, increasing cultural competence of care, formation of social support groups and networks, and improving health literacy (Callister, Beckstrand, \& Corbett, 2010). 
As a result of the concerning findings of our study and that of Lucero et al. (2012), a pamphlet has been developed containing information written in Spanish regarding PPD. Several thousand copies of the pamphlet will be distributed throughout our community with the intention of providing information that could improve health literacy and awareness of PPD. Nadeem and colleagues (2007) found that immigrant women who have stigma-related worries regarding mental illness are less likely to desire mental health treatment, so another aim of the distribution of the pamphlet is to increase knowledge that PPD is common in the community and to correct misinformation that may be present, thereby reducing PPD-associated stigma.

The daunting task of utilizing a foreign health care system is made easier if there are social support networks in place (Sanchez-Birkhead, Kennedy, Callister, \& Miyamoto, 2011). The Hispanic Labor Friends initiative described by Hazard, Callister, Birkhead, \& Nichols (2009) is an excellent example of clinicians and community members working together to improve outcomes for vulnerable women in the immigrant Hispanic community. Facilitated by clinic and hospital staff, pregnant Hispanic women were paired with trained bilingual Hispanic mothers from the local community who gave support and helped facilitate communication with health care personnel (Hazard et al., 2009). If culturally appropriate support such as this continues into the postpartum period, it may be effective in improving PPD outcomes.

Callister, Beckstrand, and Corbett (2011) made several useful recommendations for policy and program implementation regarding PPD in immigrant Hispanic women. They recommended that it become standard procedure for health care providers to assess whether pregnant immigrant Hispanic women anticipate having sufficient support following delivery. If social support is lacking, providers can become familiar with existing local support groups and refer vulnerable women and facilitate involvement as needed. Lay health workers within the 
Hispanic community may be trained to provide social support and basic preventative health education during visits to vulnerable postpartum women. Callister et al. (2010) also mention the importance of screening for PPD multiple times during the perinatal period. Practitioners who work with children can even include screening for PPD as part of their general standard of care during well-child visits.

Providers may not be aware of the high prevalence of PPD in their patients. Goldsmith (2007) asked 159 nurse practitioners regarding their experience diagnosing and treating PPD. Half of the nurse practitioners who had cared for women during the postpartum period had not even screened them once for PPD. This was in a sample where the nurse practitioners and patients shared English as their common language. Screening is even less frequent when there are communication and cultural barriers to contend with (Chaudron et al., 2005). Health providers need to be made aware of the importance of their responsibility to screen for PPD in immigrant Hispanic women, and to provide care in a culturally competent manner.

There is hope that access to PPD treatment and support in our community will improve over time. Aguilera and López (2008) searched census tracks of various Hispanic neighborhoods throughout Los Angeles and compared demographic characteristics with frequency of use of mental health services. They found that use of mental health services varied more by community rather than by proportion of foreign-born vs. U.S.-born inhabitants. The more established Hispanic communities had the highest levels of use of mental health services. Hispanic communities that have been in existence longer likely have more social networks and organizations in place to facilitate care. This increased level of mental health service seeking is found at higher levels among well-established immigrant communities regardless of income level or proportion of foreign-born v. U.S.-born inhabitants (Aguilera \& López, 2008). This has 
implications for our Utah community which appears to be composed of a large number of recent immigrants. As our local immigrant Hispanic community becomes more well-established, social networks may be formed and knowledge may be shared regarding mental health services that are available. Over time, as health seeking increases, and as health providers practice more culturally sensitive care and implement evidence-based interventions as discussed, there is hope for improvements in PPD treatment and support leading to better outcomes for individuals, children, families, and strengthening of the community as a whole. 
TABLE 1

Demographic Characteristics

\begin{tabular}{|c|c|c|c|}
\hline Characteristic & $\mathbf{N}$ & Mean (SD) & Range \\
\hline Age in Years & 59 & $28.9(5.8)$ & $17-39$ \\
\hline Number of Pregnancies & 57 & $2.8(1.38)$ & $1-7$ \\
\hline Number of Live Births & 60 & $2.6(1.2)$ & $1-5$ \\
\hline Characteristic & n (\%) & & \\
\hline $\begin{array}{l}\text { Highest Level of Education } \\
\text { Less than high school } \\
\text { Graduated from high school } \\
\text { Some college without degree } \\
\geq \text { four years of college with degree }\end{array}$ & $\begin{array}{l}9(15.3) \\
18(30.5) \\
21(35.6) \\
11(18.6)\end{array}$ & & \\
\hline $\begin{array}{l}\text { Nationality } \\
\text { Mexican } \\
\text { Central American } \\
\text { Other } \\
\end{array}$ & $\begin{array}{l}47(78.3) \\
8(13.3) \\
5(8.3)\end{array}$ & & \\
\hline $\begin{array}{l}\text { Marital Status } \\
\text { Married } \\
\text { Single } \\
\text { Divorced } \\
\text { Other } \\
\end{array}$ & $\begin{array}{l}48(80) \\
3(5) \\
2(3.3) \\
7(11.7)\end{array}$ & & \\
\hline $\begin{array}{l}\text { History of Depression } \\
\text { No } \\
\text { Yes }\end{array}$ & $\begin{array}{l}48(81.4) \\
11(18.6)\end{array}$ & & \\
\hline $\begin{array}{l}\text { Past Treatment for Depression } \\
\text { No } \\
\text { Yes } \\
\text { No response }\end{array}$ & $\begin{array}{l}54(90) \\
3(5) \\
3(5)\end{array}$ & & \\
\hline $\begin{array}{l}\text { Delivery of Youngest Child } \\
\text { Vaginal } \\
\text { Cesarean }\end{array}$ & $\begin{array}{l}49(81.7) \\
11(18.3)\end{array}$ & & \\
\hline
\end{tabular}


TABLE 2

Independent Samples Test

\begin{tabular}{|c|c|c|c|c|c|c|c|c|c|}
\hline \multirow[t]{3}{*}{ Sample } & \multicolumn{2}{|c|}{$\begin{array}{l}\text { Levene's } \\
\text { Test for } \\
\text { Equality of } \\
\text { Variances } \\
\end{array}$} & \multicolumn{7}{|c|}{ t-test for Equality of Means } \\
\hline & \multirow[t]{2}{*}{$\mathrm{F}$} & \multirow[t]{2}{*}{ Sig } & \multirow[t]{2}{*}{$\mathrm{T}$} & \multirow[t]{2}{*}{$\mathrm{Df}$} & \multirow[t]{2}{*}{ Sig } & \multirow[t]{2}{*}{$\begin{array}{l}\text { Mean } \\
\text { Diff. }\end{array}$} & \multirow[t]{2}{*}{$\begin{array}{l}\text { Std. } \\
\text { Error } \\
\text { Diff. }\end{array}$} & \multicolumn{2}{|c|}{$\begin{array}{l}\text { 95\% Confidence } \\
\text { Interval of the } \\
\text { Difference }\end{array}$} \\
\hline & & & & & & & & Lower & Upper \\
\hline $\begin{array}{l}\text { Community } \\
\mathrm{M}=75.8\end{array}$ & \multirow[b]{2}{*}{1.837} & \multirow[b]{2}{*}{.177} & \multirow[b]{2}{*}{-1.328} & \multirow[b]{2}{*}{154} & \multirow[b]{2}{*}{.186} & \multirow[b]{2}{*}{-7.18750} & \multirow[b]{2}{*}{5.41195} & \multirow[b]{2}{*}{-17.87874} & \multirow[b]{2}{*}{3.50374} \\
\hline $\begin{array}{l}\text { Clinic } \\
M=68.6\end{array}$ & & & & & & & & & \\
\hline
\end{tabular}


TABLE 3

Chi-Square Test Analysis of Total PDSS Score for Normal Adjustment v. Significant Symptoms of PPD and Location of Sample (Community v. Clinic)

\begin{tabular}{|l|l|c|c|c|c|}
\hline Interpretive Ranges & \multirow{2}{*}{$\begin{array}{l}\text { PDSS } \\
\text { Score }\end{array}$} & \multicolumn{2}{|c|}{ Sample } & \multirow{2}{*}{$\chi^{2}$ (df) } & \multirow{2}{*}{ p } \\
\cline { 3 - 4 } & $\leq 59$ & 24 & 45 & $.71(1)$ & .400 \\
\hline Normal Adjustment & & & & & \\
\cline { 1 - 4 } $\begin{array}{l}\text { Significant Symptoms of } \\
\text { Postpartum Depression }\end{array}$ & $\geq 60$ & 36 & 51 & \\
\hline
\end{tabular}


TABLE 4

Chi-Square Test Analysis of Total PDSS for Normal Adjustment v. Significant Symptoms of PPD v. Positive Screen for Major PPD and Location of Sample (Community v. Clinic)

\begin{tabular}{|c|c|c|c|c|c|}
\hline \multirow[t]{2}{*}{ Interpretive Ranges } & \multirow{2}{*}{$\begin{array}{l}\text { PDSS } \\
\text { Score }\end{array}$} & \multicolumn{2}{|c|}{ Sample } & \multirow[t]{2}{*}{$\chi^{2}$ (df) } & \multirow[t]{2}{*}{$\mathbf{p}$} \\
\hline & & Community & Clinic & & \\
\hline Normal Adjustment & $\leq 59$ & 24 & 45 & $1.6(2)$ & .448 \\
\hline $\begin{array}{l}\text { Significant Symptoms of } \\
\text { Postpartum Depression }\end{array}$ & $60-79$ & 14 & 25 & & \\
\hline $\begin{array}{l}\text { Positive Screening for Major } \\
\text { Postpartum Depression }\end{array}$ & $80 \geq$ & 22 & 26 & & \\
\hline
\end{tabular}




\section{References}

Abrams, L. S., \& Curran, L. (2011). Maternal identity negotiations among low-income women with symptoms of postpartum depression. Qualitative Health Research, 21(3), 373-385. doi:10.1177/1049732310385123

Aguilera, A., \& López, S. (2008). Community determinants of Latinos' use of mental health services. Psychiatric Services, 59(4), 408-413.

Alegría, M., Canino, G., Shrout, P., Woo, M., Duan, N., Vila, D., \& ... Meng, X. (2008).

Prevalence of mental illness in immigrant and non-immigrant U.S. Latino groups. American Journal Of Psychiatry, 165(3), 359-369.

Balcazar, H., Castro, F. G., \& Krull, J. L. (1995). Cancer risk reduction in Mexican American women: the role of acculturation, education, and health risk factors. Health Education Quarterly, 22, 61-84.

Beck, C. T. (2006). Acculturation: Implications for perinatal research. The American Journal of Maternal/Child Nursing, 31(2), 114-120.

Beck, C., \& Gable, R. (2001). Comparative analysis of the performance of the Postpartum Depression Screening Scale with two other depression instruments. Nursing Research, 50(4), 242-250.

Beck, C., \& Gable, R. (2003). Postpartum Depression Screening Scale: Spanish version. Nursing Research, 52(5), 296-306.

Beck, C. T. \& Gable, R. K. (2005a). Scoring and interpreting guide for the PDSS Spanish form. Western Psychological Services, (W-380SM).

Beck, C. T. \& Gable, R. K. (2005b). Screening performance of the Postpartum Depression Screening Scale-Spanish version. Journal of Transcultural Nursing, 16(4), 331- 338. 
Boyd, R. C., Zayas, L. H., \& McKee, M. D. (2006). Mother-infant interaction, life events and prenatal and postpartum depressive symptoms among urban minority women in primary care. Maternal and Child Health Journal, 10(2), 139-148.

Cabassa, L. J., \& Zayas, L. H. (2007). Latino immigrants’ intentions to seek depression care. American Journal of Orthopsychiatry, 77(2), 231-242.

Callister, L., Beckstrand, R., \& Corbett, C. (2010). Postpartum depression and culture: Pesado Corazon. MCN. The American Journal Of Maternal Child Nursing, 35(5), 254-261.

Callister, L., Beckstrand, R. L., \& Corbett, C. (2011). Postpartum depression and help seeking behaviors in immigrant Hispanic women. JOGNN: Journal Of Obstetric, Gynecologic \& Neonatal Nursing, 40(4), 440-449. doi:10.1111/j.1552 6909.2011.01254.x

Centers for Disease Control and Prevention. (2008). Prevalence of self-reported postpartum depressive symptoms - 17 states, 2004-2005. Retrieved from http://www.cdc.gov/mmwR/ preview/mmwrhtml/mm5714a1.htm.

Chang, E. C., Sanna, L. J., Hirsch, J. K., \& Jeglic, E. L. (2010). Loneliness and negative life events as predictors of hopelessness and suicidal behaviors in Hispanics: Evidence for a diathesis-stress model. Journal of Clinical Psychology, 66(12), 1242-1253. doi:10.1002/jclp.20721

Chaudron, L., Szilagyi, P., Tang, W., Anson, E., Talbot, N., Wadkins, H., \& ... Wisner, K. (2010). Accuracy of depression screening tools for identifying postpartum depression among urban mothers. Pediatrics, 125(3), e609-17. doi:10.1542/peds.2008-3261

Chaudron, L. H., Kitzman, H. J., Peifer, K. L., Morrow, S., Perez, L. M., \& Newman, M. C. (2005). Self-recognition of and provider response to maternal depressive symptoms in low income Hispanic women. Journal of Women’s Health, 14(4), 331-338. 
Davila, M., McFall, S. L., \& Cheng, D. (2009). Acculturation and depressive symptoms among pregnant and postpartum Latinas. Maternal and Child Health Journal, 13, 318-325.

Dennis, C., \& Chung-Lee, L. (2006). Postpartum depression help-seeking barriers and maternal treatment preferences: A qualitative systematic review. Birth, 33(4), 323-331.

Fortner, R., Pekow, P., Dole, N., Markenson, G., \& Chasan-Taber, L. (2011). Risk factors for prenatal depressive symptoms among Hispanic women. Maternal \& Child Health Journal, 15(8), 1287-1295. Doi:10.1007/s10995-010-0673-9

Fry, E. (1968). A readability formula that saves time. Journal of Reading, 11, 513-516, 575-579.

Fung, K., \& Dennis, C. (2010). Postpartum depression among immigrant women. Current Opinion in Psychiatry, 23(4), 342-348.

Garcés, I., Scarinci, I., \& Harrison, L. (2006). An examination of sociocultural factors associated with health and health care seeking among Latina immigrants. Journal of Immigrant \& Minority Health, 8(4), 377-385.

Hazard, C., Callister, L., Birkhead, A., \& Nichols, L. (2009). Hispanic Labor Friends initiative: supporting vulnerable women. MCN: The American Journal Of Maternal Child Nursing, 34(2), 115-121. doi:10.1097/01.NMC.0000347306.15950.ae

Heilemann, M. S., Frutos, L., Lee, K. A., \& Kury, F. S. (2004). Protective strength factors, resources, and risks in relation to depressive symptoms among childbearing women of Mexican descent. Health Care for Women International, 25, 88-106.

Howell, E. A., Mora, P. A., Horowitz, C. R., \& Leventhal, H. (2005). Racial and ethnic differences in factors associated with early postpartum depressive symptoms. Obstetrics and Gynecology, 105, 1442-1450.

Huang, B., Appel, H. \& Ai, A.L. (2011). The effects of discrimination and acculturation to 
service seeking satisfaction for Latina and Asian American women: Implications for mental health professionals. Social Work in Public Health, 26(1), 46-59. doi: 10.1080/ 10911350903341077

Korinek, K., \& Smith, K.R. (2011). Prenatal care among immigrant and racial-ethnic minority women in a new immigrant destination: Exploring the impact of immigrant legal status. Social Science \& Medicine,72: 1695-1703.

Kozhimannil, K., Trinacty, C., Busch, A., Huskamp, H., \& Adams, A. (2011). Racial and ethnic disparities in postpartum depression care among low-income women. Psychiatric Services, 62(6), 619-625. doi:10.1176/appi.ps.62.6.619

Lara, M., Le, H., Letechipia, G., \& Hochhausen, L. (2009). Prenatal depression in Latinas in the U.S. and Mexico. Maternal \& Child Health Journal, 13(4), 567-576. doi:10.1007/s10995 008-0379-4

Le, H. N., Perry, D. F., \& Ortiz, G. (2010). The postpartum depression screening scale-Spanish version: Examining the psychometric properties and prevalence of risk for postpartum depression. Journal of Immigrant and Minority Health, 12, 249-258.

Logsdon, M., \& Hutti, M. (2006). Readability: An important issue impacting healthcare for women with postpartum depression. MCN: The American Journal of Maternal Child Nursing, 31(6), 350-355.

Lucero, N., Beckstrand, R., Callister, L.C. \& Birkhead, A. (2012). The prevalence of postpartum depression in Hispanic immigrant women. Journal of the American Academy of Nurse Practitioners, in press to be published September, 2012.

Martinez-Schallmoser, L., Telleen, S., \& MacMullen, N. J. (2003). The effect of social support and acculturation on postpartum depression in Mexican American women. Journal of 
Transcultural Nursing, 14(4), 329-338.

McGarry, J., Kim, H., Sheng, X., Egger, M., \& Baksh, L. (2009). Postpartum depression and help-seeking behavior. Journal of Midwifery and Women's Health, 54(1), 50-56.

Miranda, J., Siddique, J., Der-Martirosian, C., Belin, T. R. (2005). Depression among Latina immigrant mothers separated from their children. Psychiatric Services, 56(6), 717-720.

Motel, S. (2012). Statistical portrait of Hispanics in the United States, 2010. Pew Hispanic Center: Washington, DC. Retrieved from http://www.pewhispanic.org/2012/02/21/ statistical-portrait-of-hispanics-in-the-united-states-2010/

Nadeem, E., Lange, J. M., Edge, D., Fongwa, M., Belin, T., \& Miranda, J. (2007). Does stigma keep poor young immigrant and U.S.-born Black and Latina women from seeking mental health care?. Psychiatric Services, 58(12), 1547-1554.

O’Hara, M. W. (2009). Postpartum depression: What we know. Journal of Clinical Psychology,65(12), 1258-1269.

Reuland, D., Cherrington, A., Watkins, G., Bradford, D., Blanco, R., \& Gaynes, B. (2009). Diagnostic accuracy of Spanish language depression-screening instruments. Annals Of Family Medicine, 7(5), 455-462. doi:10.1370/afm.981

Rich-Edwards, J. W., Kleinman, K., Abrams, A., Harlow, B. L., McLaughlin, T. J., Joffe, H., \& Gillman, M. W. (2006). Sociodemographic predictors of antenatal and postpartum depressive symptoms among women in a medical group practice. Journal of Epidemiology and Community Health, 60, 221-227.

Sanchez-Birkhead, A., Kennedy, H., Callister, L., \& Miyamoto, T. (2011). Navigating a new health culture: Experiences of immigrant Hispanic women. Journal Of Immigrant \& Minority Health, 13(6), 1168-1174. doi:10.1007/s10903-010-9369-x 
Sit, D. K. Y., \& Wisner, K. L. (2009). Identification of postpartum depression. Clinical Obstetrics and Gynecology, 52(3), 456-468.

Surkan, P. J., Peterson, K. E., Hughes, M. D., \& Gottlieb, B. R. (2006). The role of social networks and support in postpartum women's depression: A multiethnic urban sample. Maternal and Child Health Journal, 10(4), 375-383.

Thomson, M. D., \& Hoffman-Goetz, L. (2009). Defining and measuring acculturation: A systematic review of public health studies with Hispanic populations in the United States. Social Science and Medicine, 69, 983-991.

Wallace, P. M., Pomery, E. A., Latimer, A. E., Martinez, J. L., \& Salovey, P. (2010). A review of acculturation measures and their utility in studies promoting Latino health. Hispanic Journal of Behavioral Sciences, 32(1), 37-54.

Zayas, L. H., Lester, R. J., Cabassa, L. J., \& Fortuna, L. R. (2005). Why do so many Latina teens attempt suicide? A conceptual model for research. American Journal of Orthopsychiatry, 75(2), 275-287. doi:10.1037/0002-9432.75.2.175

Zayas, L. H., \& Pilat, A. M. (2008). Suicidal behavior in Latinas: Explanatory cultural factors and implications for intervention. Suicide \& Life-Threatening Behavior, 38(3), 334-342. 